\title{
A TRADIÇÃO ORAL E 0 APARECIMENTO DA FICÇÃO
}

http://dx.doi.org/10.11606/issn.2237-1184.v0i30p163-171

Eduardo Vieira Martins ${ }^{I}$

\section{RESUMO}

A partir de uma questão sugerida por Antonio Candido na Formação da literatura brasileira - a dificuldade que os escritores tiveram para elaborar um estilo adequado à representação dos costumes das comunidades do interior do país, inclusive dos dialetos regionais, desviantes da norma culta da língua portuguesa - este artigo tem o objetivo de discutir algumas estratégias empregadas por Bernardo Guimarães para incorporar a tradição oral no romance, um gênero culto e vinculado ao livro, destinado ao público leitor urbano.

\section{ABSTRACT}

Engaging with an issue raised by Antonio Candido in Formação da literatura brasileira - the difficulty writers had to develop an appropriate style in order to represent the customs of the communities from the interior of the country, including the regional dialects that deviate from standard Portuguese - , this article aims to discuss some of the strategies adopted by Bernardo Guimarães so as to incorporate the oral tradition in the novel, a genre associated with the world of print and intended for the urban reading public.

\section{PALAVRAS-CHAVE:}

Antonio Candido;

romance;

história literária;

Romantismo;

Bernardo Guimarães.

\section{KEYWORDS}

Antonio Candido;

novel;

literary history;

Romanticism;

Bernardo Guimarães.

I Universidade de São Paulo, São Paulo, São Paulo, Brasil. 


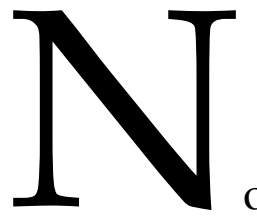

o segundo volume da Formação da literatura brasileira, no capítulo intitulado "Aparecimento da ficção", Antonio Candido desenvolve uma pequena teoria sobre a introdução do romance no Brasil do século XIX, chamando a atenção para sua importância no processo de construção da imagem da nação. ${ }^{1}$ Compreendido pelo crítico como um gênero "mais ou menos equidistante da pesquisa lírica e do estudo sistemático da realidade", o romance foi utilizado como "um instrumento de descoberta e interpretação" (CANDIDO, 1981, p. 109), que possibilitou cartografar paisagens e tipos humanos que deveriam integrar o império: "No período romântico", diz ele, "a imaginação e a observação de alguns ficcionistas ampliaram largamente a visão da terra e do homem brasileiro" (Idem, p. 112). O jogo entre "imaginação" e "observação", entre pesquisa e invenção, estaria na base do romance romântico, possibilitando suas melhores realizações, mas, ao mesmo tempo, impondo um problema que, como veremos a seguir, precisaria ser equacionado pelos escritores. Ao fazer o balanço da prosa de ficção produzida no período, o crítico afirma:

o nosso romance tem fome de espaço e uma ânsia topográfica de apalpar todo o país. Talvez o seu legado consista menos em tipos, personagens e peripécias do que em certas regiões tornadas literárias, a sequência narrativa inserindo-se no ambiente, quase se escravizando a ele. Assim, o que se vai formando e permanecendo na imaginação do leitor é um Brasil colorido e multiforme, que a criação artística sobrepõe à realidade geográfica e social. (p. 114)

Prosseguindo a análise, Candido considera que o apego à cor local, consubstanciado no indianismo e no regionalismo, instaurou no romance uma tensão entre, de um lado, a concepção romântica do enredo e da psicologia das personagens e, de outro, o intuito programático de incorporar dados colhidos pela observação, colocando os escritores diante do desafio de encontrar a "expressão literária adequada" a cada um desses subgêneros. Confrontados por essa espécie de esfinge, o crítico avalia que a matéria indianista era mais fácil de ser trabalhada pelos escritores, favorecidos pelo modelo prestigioso de Chateaubriand e pelo fato de que o público urbano, na maior parte, simplesmente desconhecia as tribos indígenas. "No caso do regionalismo, porém, a língua e os costumes descritos eram próximos dos da cidade, apresentando difícil problema de

\footnotetext{
1 Utilizo o conceito de nação como uma "comunidade imaginada", formulado por Benedict Anderson na década de 1980, posteriormente, portanto, à publicação do livro de Candido. Ver ANDERSON, B. Nação e consciência nacional. São Paulo: Ática, 1989.
} 
estilização", o que tornava mais complexa "a obtenção da verossimilhança" (p. 116). Essa situação é tematizada no conto "Juca, o tropeiro", do Visconde de Taunay, que lança mão do expediente corriqueiro de atribuir o relato a uma fonte que o escritor-narrador teria conhecido ao longo de suas andanças, no caso, a um ex-sargento do exército. Diante do encanto provocado pela história que lhe foi transmitida, o narrador do conto se vê diante do dilema de conservá-la na sua forma linguística original, eivada de erros e impropriedades, ou de filtrá-la e conformá-la às normas cultas do público leitor ao qual se dirige: "Havendo contudo reconhecido a originalidade e força de colorido dessa linguagem, e desejando conservar ainda um quê da ingênua, mas pitoresca expressão do narrador, resultou uma coisa esquisita, nem como era contada pelo ex-sargento, nem como deveria ser, saída da mão de quem se atira a escrever para o público" (p. 116).

Partindo dessas considerações de Antonio Candido, que colocam em evidência a dificuldade de construção do romance romântico, gostaria de analisar brevemente como o choque entre o oral e o escrito, um dos elementos implicados na tensão entre o dado particular, colhido pela observação, e sua adaptação ao modelo narrativo tomado da tradição letrada, manifesta-se num escritor específico, Bernardo Guimarães. A análise que será brevemente reproduzida aqui encontra-se na minha tese de livre-docência, intitulada "Os lugares do sertão e outros estudos", defendida no Departamento de Teoria Literária e Literatura Comparada da FFLCH-USP em setembro de 2017.2

O ermitão do Muquém (1869), de Bernardo Guimarães, conta a história da romaria que todo ano se dirige à capela de Nossa Senhora da Abadia, localizada no interior da província de Goiás, e de Gonçalo, seu fundador. Já no prólogo, o "autor" afirma que a história que irá contar "repousa sobre uma tradição real mui conhecida na província de Goiás" (GUIMARÃES, 1972, p. 133)3 e esclarece a configuração dada ao livro, que se divide em três grandes partes, cada uma delas com um estilo próprio, sugerido pelas diferentes situações enfrentadas pelo protagonista. "A primeira parte", ambientada em Vila Boa, "é escrita no tom de um romance realista e de costumes; representa cenas da vida dos homens do sertão, seus folguedos ruidosos e um pouco bárbaros, seus costumes licenciosos, seu espírito de valentia e suas rixas sanguinolentas" (Idem, p. 133).

\footnotetext{
${ }^{2}$ MARTINS, E. V. Os lugares do sertão e outros estudos. Tese de livre-docência. FFLCH-USP (2017). Uma versão mais desenvolvida da análise resumida nesta comunicação foi apresentada no XIV Congresso Internacional da Abralic (UFPA, 2015), com o título de "A musa sertaneja: Bernardo Guimarães e o romance do sertão".

3 Todas as citações do romance são feitas a partir dessa edição.
} 
Contrastando com essa abertura, a segunda parte retrata a vida do herói entre os índios, cujos costumes desconhecidos impediriam a adoção da perspectiva realista e obrigariam o romance a tomar certos "certos ares de poema" (p. 133):

O realismo de seu viver nos escapa, e só nos resta o idealismo, e esse mesmo mui vago, e talvez em grande parte fictício. Tanto melhor para o poeta e o romancista; há largas ensanchas para desenvolver os recursos de sua imaginação. O lirismo, pois, que reina nesta segunda parte, [...] é muito desculpável; esse estilo um pouco mais elevado e ideal era o único que quadrava aos assuntos que eu tinha que tratar, e às circunstâncias de meu herói. (p. 133-4)

Finalmente, a terceira parte do romance, ao tratar da fundação da abadia, aborda o "cristianismo", um tema de "ideal sublimidade", que exige um estilo mais elevado, um "tom mais grave e mais solene, uma linguagem como essa que Chateaubriand e Lamartine sabem falar quando tratam de tão elevado assunto" (p. 134).

Conforme o herói se desloca do povoado de Vila Boa para as tribos indígenas e daí para o sertão profundo, onde erige a capela em louvor a Nossa Senhora da Abadia, o narrador se depara com o problema analisado por Antonio Candido no capítulo da Formação comentado anteriormente, a saber, a formulação do estilo adequado a cada gênero. No caso de $O$ ermitão do Muquém, a busca do decoro é equacionada como um percurso de ascensão estilística: enquanto a primeira parte do romance é composta em estilo médio, apto a representar, de perspectiva "realista", "a sociedade tosca e grosseira do sertanejo" (p. 133), a segunda reveste-se de um "estilo um pouco mais elevado", adotando uma linguagem poética adequada à idealização da vida indígena, até que, por fim, a terceira parte assume um "tom mais grave e solene", um estilo afeito à "ideal sublimidade do assunto", o "misticismo cristão" (p. 134).

O ermitão do Muquém é estruturado como uma narrativa de encaixe. Há uma moldura, na qual um primeiro narrador relata a viagem que fazia de Goiás ao Rio de Janeiro, quando, ao atravessar a província de Minas Gerais, encontra-se casualmente com um romeiro oriundo do Muquém, que se integra à caravana $e$, nas quatro noites em que param para descansar, conta a história da fundação da capela de Nossa Senhora da Abadia. ${ }^{4}$ Para garantir a veracidade do relato, esse romeiro é descrito como um homem franco e educado; ele possuía "imaginação viva, inteligência clara e sua linguagem e maneiras revelavam um espírito cultivado e fina educação. Nos olhos e na boca tinha notável expressão de bondade e

\footnotetext{
${ }^{4}$ As três partes do romance referidas no prólogo distribuem-se da seguinte maneira: a primeira parte corresponde ao Pouso Primeiro; a segunda, aos Pousos Segundo e Terceiro; a terceira, ao Pouso Quarto.
} 
franqueza; sua voz era de um timbre claro e sonoro. Nada pois faltava ao nosso narrador para prender todas as atenções" (p. 141). Ao terminar o relato, o romeiro-narrador confirma a veracidade dos fatos reportados e assegura a fidedignidade da fonte por meio da qual tomou conhecimento da história:

Se queres saber onde fui eu ter conhecimento tão por miúdo dos acontecimentos desta verídica narração, sabeis que eu a ouvi de um velho romeiro, que a tinha ouvido da boca do próprio mestre Mateus, e que a ouvi junto às ruínas da choça do santo ermitão, sentado sobre o mesmo cepo em que este outrora a tinha contado ao velho ferreiro de Goiás e à sua família de romeiros. (p. 273)

O primeiro narrador, responsável pela moldura delineada na "Introdução", afirma ter conhecido a história por meio do romeiro, que por sua vez a ouviu de outro fiel, a quem ela havia sido contada por mestre Mateus, que em parte a testemunhou e em parte foi informado dos seus episódios através do relato de Gonçalo. Dessa maneira, procura-se vincular o romance a uma tradição oralmente transmitida, finalmente recolhida e fixada pelo escritor, que busca mimetizar no livro algumas marcas de oralidade, muito particularmente a divisão em Pousos, que corresponderiam às noites em que a história foi narrada pelo romeiro. Daí a aparência de "causo", perceptível em diversos romances de Bernardo Guimarães, que, nas palavras de Antonio Candido, "parecem boa prosa da roça, [...] sem outro ritmo além do que lhes imprime a disposição de narrar sadiamente, com simplicidade, o fruto de uma pitoresca experiência humana e artística" (CANDIDO, op. cit., p. 236).

A mistura entre o oral e o escrito torna mais agudo o problema da incorporação, por parte do romance moderno, de elementos tomados à lenda, forma arcaica que, no caso de O ermitão do Muquém, conservaria na memória popular a história da fundação da abadia erguida nos confins de Goiás. Para Erich Auerbach, diferentemente do modo histórico, que trabalha com diversos planos e procura dar conta das contradições e da complexidade de cada momento vivido, quando uma plêiade de possibilidades apresenta-se a um sujeito vacilante e incerto, a lenda apresenta um caráter linear e unívoco, tendendo a aplainar os conflitos e a avançar sem hesitação em direção ao desenlace (AUERBACH, 1976, p. 156). No Ermitão, a estrutura lendária se manifesta em diversos níveis, seja na incorporação de motivos tradicionais, como o triângulo amoroso, a missão perigosa, concebida como prova de valor, e o combate de morte, seja na perspectiva adotada pelo narrador, que tende a dirimir os conflitos internos, dando lugar a personagens planas, o mais das vezes repartidas entre o bem e o mal, ou oscilando entre esses dois polos, num movimento que eventualmente pode dilacerar a personalidade, como acontece com Gonçalo. Dessa maneira, o aspecto inteiriço e unívoco das personagens não 
precisa ser avaliado como defeito da narrativa ou como inépcia do escritor, podendo ser compreendido como resultado da incorporação de um elemento estrutural da lenda, que colaborou para a consecução de efeitos visados pelo romance do século XIX, notadamente para a edificação do público leitor. Ao lado desses elementos tradicionais e de possível transmissão oral, o relato também se apropria de fontes eruditas, desde a escolha do gênero romance e do diálogo explícito com Chateaubriand e outros escritores do século XIX, sobretudo Byron, até a construção do herói como uma personagem cindida.

O problema da obtenção do estilo adequado à incorporação do relato oral pelo romance - que remete à discussão de "Juca, o tropeiro" feita por Antonio Candido - , aparece não apenas no Ermitão, mas também em "A dança dos ossos", publicado por Bernardo Guimarães em Lendas e romances (1871). Nesse conto, o narrador culto e urbano afirma que a história lhe foi contada por um rústico barqueiro e lamenta que o relato escrito não fosse capaz de conservar a vivacidade e o colorido da sua fala: "O velho barqueiro contava esta tremenda história de modo mais tosco, porém muito mais vivo do que eu acabo de escrevê-la, e acompanhava a narração de uma gesticulação selvática e expressiva de sons imitativos que não podem ser representados por sinais escritos" ${ }^{5}$

Além dessa tensão entre o oral e o escrito, entre a expressividade da voz e do gesto, de um lado, e a frieza da letra impressa, de outro, Bernardo Guimarães estava atento a outro problema: o da recepção do universo rústico do sertão, que ele se esforçava por constituir como matéria narrativa, no mundo polido da cidade, onde seus livros eram consumidos. O problema é explicitado em $O$ índio Afonso (1873), publicado quatro anos depois do Ermitão. No primeiro capítulo do livro, ao destacar o caráter dúplice das "fundas e emaranhadas selvas dos sertões de nossa terra", que, ao mesmo tempo em que abrigam "riquezas e curiosidades naturais", são palco de aventuras marcadas pelo horror e pelo mistério, observa que essas histórias não eram acessíveis ao público urbano, que as ignorava não apenas em decorrência da distância que os separava, mas principalmente devido às diferenças culturais que havia entre eles (GUIMARÃES, 1944, p. 363). O narrador, que afirma ter uma musa "sertaneja" (Idem, p. 364)6, apresenta-se como uma espécie de tradutor, um intermediário entre dois universos distantes e distintos, o sertanejo, de maravilhas e horrores, do sublime e do grotesco, e o urbano, da cultura letrada. Ao referir-se às histórias estupendas sepultadas no fundo das florestas, observa:

${ }^{5}$ GUIMARÃES, B. “A dança dos ossos". In: Lendas e romances. Ed. cit., p. 214. Grifo meu.

6 "A minha musa é essencialmente sertaneja; sertaneja de nascimento, sertaneja por hábito, sertaneja por inclinação". 
Mas o segredo de tais histórias as alimárias guardam consigo e se o contam lá entre si, é em uma linguagem que ninguém pode compreender.

$\mathrm{Eu}$, entretanto, que às vezes tenho conversado como o grande espírito das florestas, [...] estou um pouco habilitado para interpretar, ainda que imperfeitamente, essa linguagem, e poderei contar-vos, amáveis leitoras, algumas dessas tremendas histórias. (p. 363)

A dificuldade que se coloca, então, é encontrar a maneira adequada de narrar "tremendas histórias" para "amáveis leitoras", habituadas ao conforto da corte e aos encantos dos romances de salão. Como superar essa barreira? Pelos comentários desenvolvidos pelo narrador de O índio Afonso, pode-se depreender que ele vislumbrava dois caminhos. Primeiramente, afirma que, para conduzir confortavelmente suas leitoras ao sertão, vai tomar o carro da "deusa Fantasia": "Dentro desses caleches as lindas e delicadas damas poderão acompanhar-me até ao fundo dos meus remotos e bravios sertões, sem perigo algum e sem fadiga, que é o que mais ambiciono" (p. 365). Como o prólogo do livro borra os limites entre o fato e o relato, e depois de sustentar que o protagonista era um personagem real, que o autor teve ocasião de conhecer, termina pela afirmação de que "o Índio Afonso de meu romance não é o facínora de Goiás; é pura criação de minha fantasia" (p. 362), parece possível supor que, para ele, os dados da observação deveriam ser trabalhados pela imaginação de maneira a adequá-los às convenções literárias que compunham o repertório do público, possibilitando o contato do leitor urbano com o universo sertanejo.

O segundo recurso utilizado em $O$ indio Afonso para tornar as histórias sertanejas aceitáveis para o leitor culto consiste em narrar os seus horrores diretamente, porém, de forma concisa. Assim, apesar de dizer que "os dedos me tremem convulsos e a pena arrepiada de horror range-me sobre o papel, ao encetar a narração da hedionda cena que vai seguir" ( $\mathrm{p}$. 378), relata sem meias palavras a brutal vingança imposta por Afonso a Turuna, o homem que tentou violentar sua irmã, mas não se alonga em descrições detalhadas:

Confesso que não sei que expressões hei de empregar para contar aos leitores, e especialmente às delicadas e sensíveis leitoras, estas cenas de canibalismo e de horror, e vejo-me em tais embaraços, que já me arrependo de ter encetado a história de tão sinistro e revoltante drama.

Com todo o sossego e impassibilidade, como quem destrinça um porco morto, Afonso levou a faca às carnes do mísero Turuna. Depois de o ter castrado de um só golpe, cortou-lhe os beiços, o nariz e as orelhas. Corro sobre estas palavras com quem passa sobre as brasas de uma fogueira, se bem que Afonso praticasse 
todas aquelas bárbaras amputações com todo o vagar e com a mais horrível fleuma e sangue frio. (p. 379)

Note-se que o horror não é omitido, mas, ao "corr[er] sobre estas palavras", o narrador adota um estilo conciso, que lhe parece o mais conveniente às suas "delicadas e sensíveis leitoras", cujo desconforto seria aprofundado por descrições minuciosas e por uma difusão do discurso. Além disso, a focalização direta coloca a cena em primeiro plano e não deixa nada sob a sombra, provavelmente porque considerasse que o desconhecido pudesse se afigurar mais ameaçador do que o próprio horror visto e delimitado com clareza.

$O$ viés fornecido pela fantasia, explicitado em $O$ índio Afonso, já se manifestava em $O$ ermitão do Muquém, não apenas na parte do relato dedicada à efabulação da vida indígena, como sugeria o prólogo do livro, mas também nas cenas em que Gonçalo aparece em Vila Boa e na ermida da floresta. Contudo, ao contrário da focalização crua e direta, perceptível na cena da vingança de Afonso contra Turuna, o que caracteriza $O$ ermitão do Muquém é uma forma alusiva e indireta utilizada pelo narrador para falar dos aspectos mais chocantes da história sem ferir a sensibilidade e a moral dos leitores urbanos, sobretudo do tão prezado e fiel público feminino, grande consumidor de livros e folhetins. Assim como na adequação do estilo à situação vivenciada pelo herói em cada parte do romance, referida no prólogo do Ermitão, há nesse modo, por assim dizer, "discreto" de narrar (que não é possível caracterizar no breve espaço deste artigo), uma preocupação com o decoro, compreendido agora como observação às conveniências devidas ao público para o qual o livro se destina. As diferentes maneiras de trabalhar a matéria sertaneja e apresentá-la ao leitor urbano deixam entrever o enfrentamento, por parte de Bernardo Guimarães, da dificuldade de obtenção do estilo mais adequado à fixação dos costumes das comunidades do interior do país, problema discutido por Candido no capítulo da Formação que nos serviu de ponto de partida. 


\section{Referências bibliográficas}

AUERBACH, E. Mimesis. São Paulo: Perspectiva, 1976.

CANDIDO, A. Formação da literatura brasileira. Belo Horizonte: Itatiaia, 1981, v. 2.

GUIMARÃES, B. O ermitão do Muquém. Ed. crítica por Antônio José Chediak. Brasília: INL, 1972.

GUIMARÃES, B. O índio Afonso. In: Quatro romances. São Paulo: Livraria Martins, 1944.

Eduardo Vieira Martins é professor associado do Departamento de Teoria Literária e Literatura Comparada da Faculdade de Filosofia, Letras e Ciências Humanas da Universidade de São Paulo. É autor do livro A fonte subterrânea - José de Alencar e a retórica oitocentista (2005). Contato: eduardovm@usp.br

ORCiD: https:// orcid.org/0000-0001-8681-1901 